\title{
Growth and characterization of pure and doped NLO L-arginine acetate single crystals
}

\author{
P PRAVEEN KUMAR ${ }^{\dagger}$, V MANIVANNAN ${ }^{\dagger}$, P SAGAYARAJ and J MADHAVAN* \\ Department of Physics, Loyola College, Chennai 600 034, India \\ ${ }^{\dagger}$ Department of Physics, Presidency College, Chennai 600 005, India
}

MS received 11 August 2008; revised 8 October 2008

\begin{abstract}
Single crystals of pure, $\mathrm{Cu}^{2+}$ and $\mathrm{Mg}^{2+}$ doped L-arginine acetate (LAA) were grown successfully by slow evaporation technique. In order to improve the device characteristics of LAA crystals, metal dopants of $\mathrm{Cu}^{2+}$ and $\mathrm{Mg}^{2+}$ were incorporated into the parent crystals. The grown pure and doped crystals were confirmed by X-ray powder diffraction studies. The pure and doped crystals were characterized by Fourier transform Raman (FT-Raman) and thermal studies. Absorptions of these grown crystals were analysed using UV-VisNIR studies, and it was found that these crystals possess minimum absorption in the entire visible region. Nonlinear optical studies of pure and doped crystals were carried out and it reveals that the dopants have increased the efficiency of LAA crystals.
\end{abstract}

Keywords. NLO; SHG; solution growth; LAA

\section{Introduction}

L-arginine phosphate monohydrate (LAP) was first reported by $\mathrm{Xu}$ et al (1983) as a promising nonlinear optical (NLO) material. LAP is nearly three times more nonlinear than KDP. Monaco et al (1987) reported the formation of LAP and its chemical analogs from the strongly basic amino acid and various other acids. Nonlinear optical (NLO) organic materials play an important role for optical second harmonic generation (SHG) due to their applications in the domain of optoelectronics and photonics (Saleh and Teich 1991; Boyd 1992). Amino acids are strong candidates for optical second harmonic generation (SHG) because they contain chiral carbon atom and crystallizes in non-centrosymmetric space groups. Amino acid crystal, L-arginine acetate (LAA), has been reported as a promising NLO material by Pal et al (2003). Larginine acetate (LAA) has powder SHG efficiency nearly three times that of KDP (Muralidharan et al 2003). In the present work, attempts have been made to improve the physicochemical properties by incorporating metal dopants. A systematic study has been carried out on the growth of pure and metal $\left(\mathrm{Cu}^{2+}\right.$ and $\left.\mathrm{Mg}^{2+}\right)$ doped LAA crystals. Powder X-ray diffraction studies were carried out and the lattice parameters of the grown pure and doped crystals are evaluated. The content of $\mathrm{Cu}$ and $\mathrm{Mg}$ has been determined by atomic absorption studies. FTRaman, UV-Vis-NIR, and thermal studies were carried out for the grown pure and doped crystals. The SHG effi-

*Author for correspondence (jmadhavang@yahoo.com) ciency of the pure and doped LHA crystals were also studied using Nd: YAG Q-switched laser.

\section{Experimental}

\subsection{Synthesis, purification and crystal growth}

Aqueous solution of pure, $\mathrm{Cu}^{2+}$ and $\mathrm{Mg}^{2+}$ doped LAA were prepared by dissolving stoichiometric L-arginine (AR grade) and acetic acid in double deionized water. The pure and doped LAA crystals were grown by slow evaporation technique at room temperature $\left(30^{\circ} \mathrm{C}\right)$. The reaction that takes place between L-arginine and acetic acid in water medium is as follows:

$$
\begin{gathered}
\left(\mathrm{NH}_{2}\right) \mathrm{NHCNH}\left(\mathrm{CH}_{2}\right)_{3} \mathrm{CH}\left(\mathrm{NH}_{2}\right) \mathrm{COOH}+\mathrm{CH}_{3} \mathrm{COOH} \rightarrow \\
\left(\mathrm{NH}_{2}\right)_{2}^{+} \mathrm{CNH}\left(\mathrm{CH}_{2}\right)_{3} \mathrm{CH}\left(\mathrm{NH}_{3}\right)^{+} \mathrm{COO}^{-} \mathrm{CH}_{3} \mathrm{COO}^{-} .
\end{gathered}
$$

Figure 1 shows the photograph of the as grown pure and doped crystals in a period of 50 days. The crystals are found to be transparent and free from defects. The growth of metal substituted crystal is achieved by using the same procedure by adding dopants of 2 mole $\%$ concentration (each) of $\mathrm{Cu}^{2+}$ and $\mathrm{Mg}^{2+}$ to the LAA solution.

\section{Characterization}

\subsection{Atomic absorption studies}

$10 \mathrm{mg}$ of fine powder of the doped LAA crystals was dissolved in $100 \mathrm{ml}$ of triple distilled water, respectively 

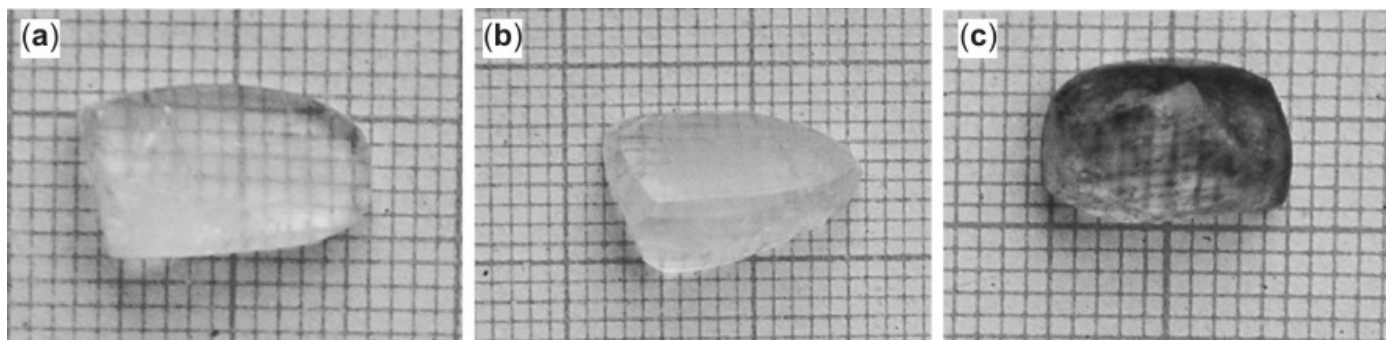

Figure 1. Photographs of as grown (a) pure LAA, (b) $\mathrm{Cu}^{2+}$ doped LAA and (c) $\mathrm{Mg}^{2+}$ doped LAA crystals.
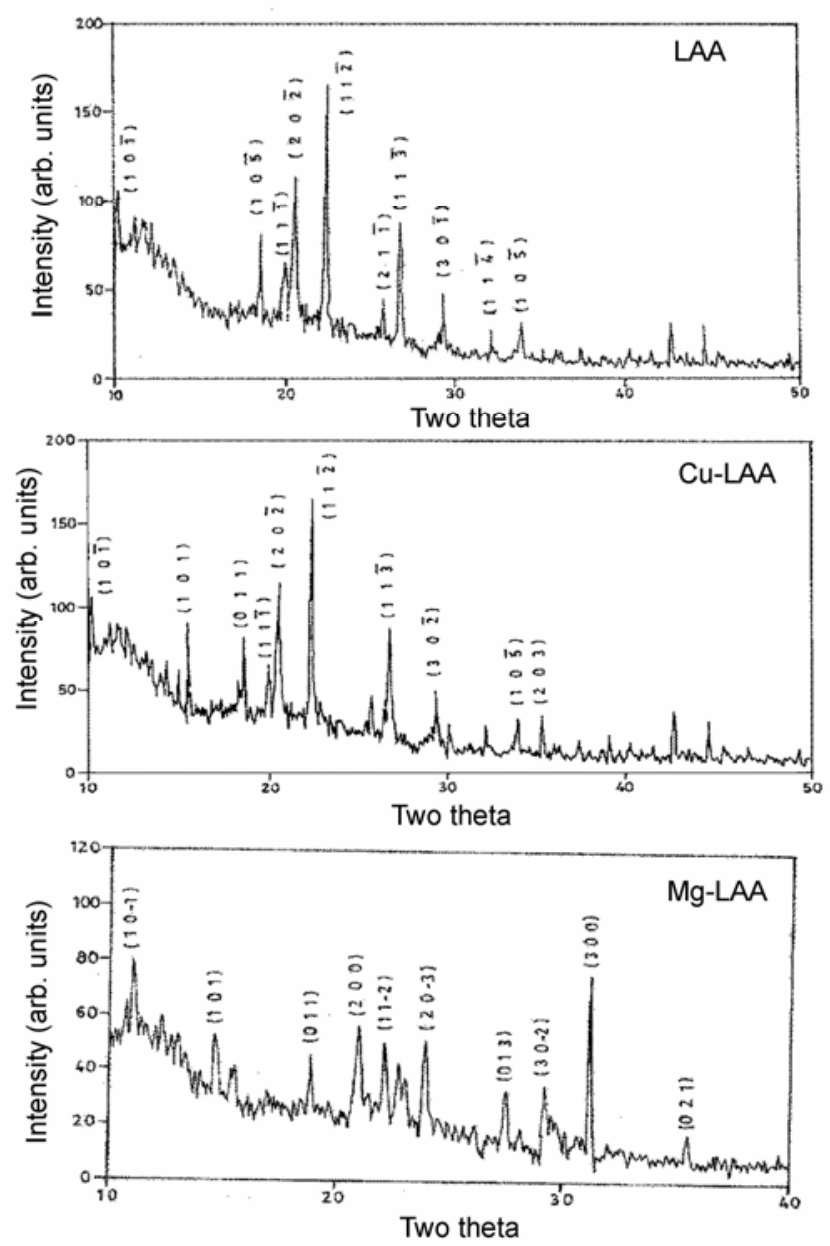

Figure 2. Powder X-ray diffraction pattern of LAA, $\mathrm{Cu}-\mathrm{LAA}$ and $\mathrm{Mg}-\mathrm{LAA}$.

and the prepared solutions were subjected to atomic absorption spectroscopy (AAS) analysis. The results showed that $0.24 \mu \mathrm{g} / \mathrm{ml}$ and $1.03 \mu \mathrm{g} / \mathrm{ml}$ are present in the respective samples. The weight percentage of the metal present will be equal to (concentration $\times$ volume)/weight of the sample. The calculation shows that only $0 \cdot 24 \%$ of $\mathrm{Cu}^{2+}$ and $1.03 \%$ of $\mathrm{Mg}^{2+}$ are present in the respective samples, out of $2 \%$ of the dopant. It is seen that the amount of dopant incorporated into the doped crystal is less than the concentration of the dopant in the corre- sponding solution. It is also seen that more $\mathrm{Mg}$ ions have gone into the LAA lattice compared to $\mathrm{Cu}$ ions. This may be due to the radius of $\mathrm{Mg}(0.65 \AA)$ compared to $\mathrm{Cu}$ ions (0.72 Å) (Haja Hameed et al 1999).

\subsection{XRD studies}

Powder X-ray diffraction studies of pure and $\mathrm{Cu}^{2+}$ and $\mathrm{Mg}^{2+}$ doped LAA crystals were carried out using Siemens D500 X-ray diffractometer with $\mathrm{CuK}_{\alpha}(\lambda=1.5418 \AA$ ) radiation. The samples were scanned for $2 \theta$ values from $10^{\circ}-70^{\circ}$ at a rate of $2 \% \mathrm{~min}$. Figure 2 shows the powder XRD pattern of the pure and doped LAA crystals. The powder patterns were indexed and the lattice parameter values for the pure and doped LAA crystals were calculated by fitting the XRD data with 'least square method' using 'XRDA' program. It is observed that both the pure and doped crystals crystallize in monoclinic $P 2_{1}$ space group. The lattice parameters of the samples are presented in table 1 along with the reported values (Muralidharan et al 2003). There are slight variations in the lattice parameters and cell volume of the pure and doped crystals. These variations are due to the incorporation of $\mathrm{Cu}^{2+}$ and $\mathrm{Mg}^{2+}$ in the LAA crystal lattice.

\section{$3.3 \quad$ FT-Raman spectra}

In order to qualitatively analyse the presence of functional groups in LAA, the polarized Fourier transform Raman (FT-Raman) spectra were recorded for the pure and doped LAA in the range $50-3500 \mathrm{~cm}^{-1}$. The recorded spectra are shown in figure 3 . The $\mathrm{NH}_{3}^{+}$stretching frequencies are found between 3100 and $2600 \mathrm{~cm}^{-1}$ in the form of a broad strong band with multiple peaks. The characteristic band at $1579 \mathrm{~cm}^{-1}$ is due to the asymmetric $\mathrm{NH}_{3}$ deformation. The weak absorption band observed at $3065 \mathrm{~cm}^{-1}$ shows the $\mathrm{N}-\mathrm{H}$ stretching of amino group. It is inferred from the peaks at $1283 \mathrm{~cm}^{-1}, 1415 \mathrm{~cm}^{-1}$ and $1626 \mathrm{~cm}^{-1}$ that they are due to the $\mathrm{C}=\mathrm{O}$ stretching of carboxylic group. The absence of peak at $1626 \mathrm{~cm}^{-1}$ for $\mathrm{C}=\mathrm{O}$ stretching in the $\mathrm{Cu}$-LAA may be due to the metal linkage with the carboxylic group. The Mg-LAA spectra shows that absence of peak at $2125 \mathrm{~cm}^{-1}$ which may be responsible for metal linkage with $\mathrm{N}$ of amino group. 
Table 1. Lattice parameter values for the pure and doped LAA.

\begin{tabular}{lllll}
\hline Lattice parameters & Pure LAA & $\mathrm{Cu}^{2+}-\mathrm{LAA}$ & $\mathrm{Mg}^{2+}-\mathrm{LAA}$ & Reported values \\
\hline$a(\AA)$ & $9 \cdot 29$ & $9 \cdot 21$ & $9 \cdot 11$ & $9 \cdot 226$ \\
$b(\AA)$ & $5 \cdot 09$ & $5 \cdot 21$ & $5 \cdot 10$ & $5 \cdot 243$ \\
$c(\AA)$ & $13 \cdot 1$ & $12 \cdot 8$ & $12 \cdot 78$ & $13 \cdot 049$ \\
$\alpha^{\circ}$ & 90 & 90 & 90 & 90 \\
$\beta^{\circ}$ & $109 \cdot 61$ & $107 \cdot 66$ & $107 \cdot 85$ & $108 \cdot 92$ \\
$\gamma^{\circ}$ & 90 & 90 & 90 & 90 \\
Crystal system & Monoclinic & Monoclinic & Monoclinic & Monoclinic \\
Space group & $P 2_{1}$ & $P 2_{1}$ & $P 2_{1}$ & $P 2_{1}$ \\
Volume $\left(\AA^{3}\right)$ & $586 \cdot 20$ & $581 \cdot 38$ & $570 \cdot 73$ & $597 \cdot 14$ \\
\hline
\end{tabular}
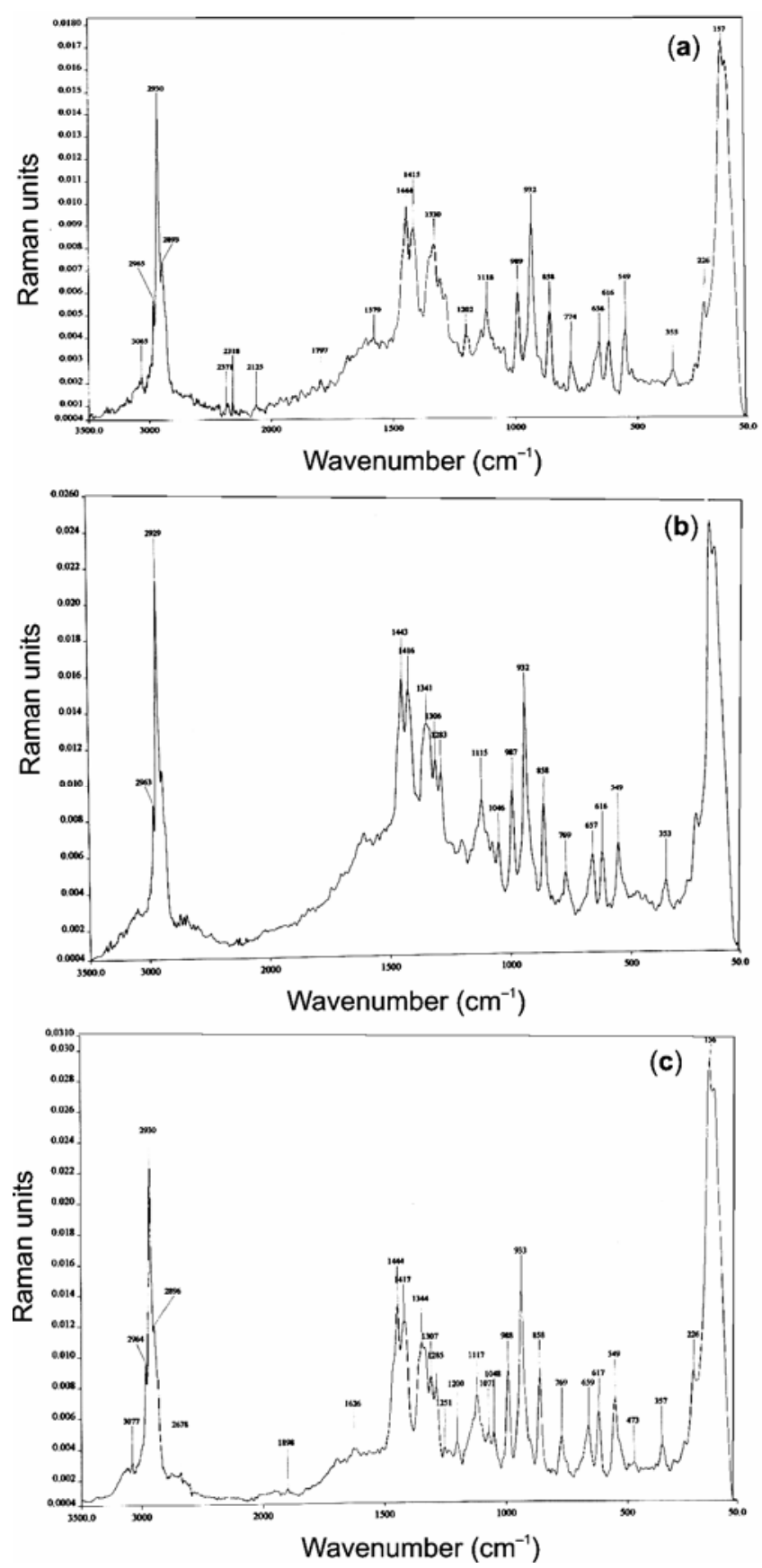

Figure 3. FT-Raman spectra of (a) pure LAA, (b) $\mathrm{Cu}^{2+}$ doped LAA and (c) $\mathrm{Mg}^{2+}$ doped LAA.

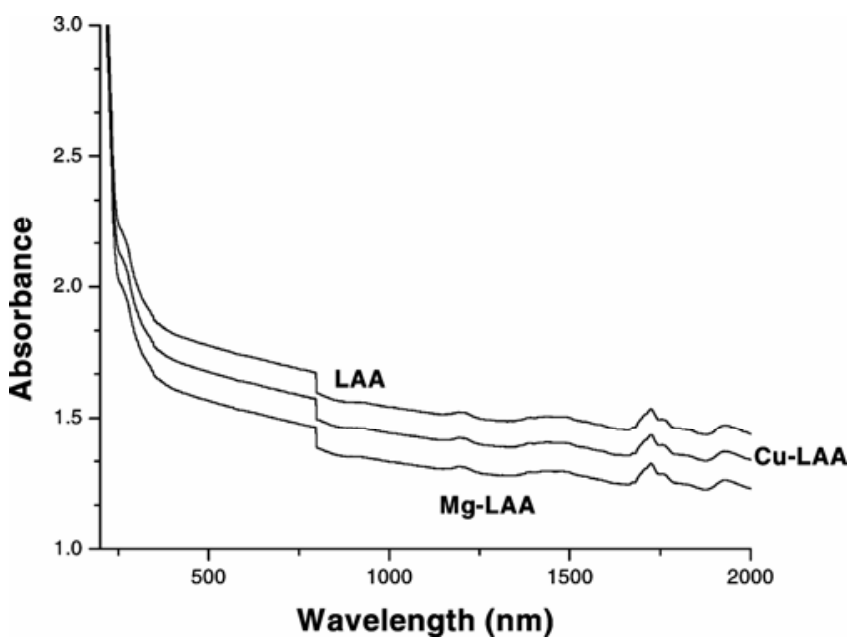

Figure 4. Optical absorption spectra of pure, $\mathrm{Cu}^{2+}$ and $\mathrm{Mg}^{2+}$ doped LAA

\section{$3.4 U V-V i s-N I R$ spectra}

Optical absorption data were taken on these polished crystal samples of about 4-6 mm thickness using a Varian carry $5 \mathrm{E}$ model dual beam spectrophotometer between 200 and $2000 \mathrm{~nm}$. The spectra (figure 4) indicate that the pure and doped LAA crystals have minimum absorption in the entire visible region. From the spectra, it is also seen that the pure and doped LAA crystals have better lower cut-off wavelengths. Interestingly, both the $\mathrm{Cu}^{2+}$ and $\mathrm{Mg}^{2+}$ doped crystals have decreased absorption. The required properties for NLO activity are minimum absorption and low cut-off wavelength. These properties are improved in the doped crystals.

\subsection{NLO studies}

The grown crystals of pure and doped LAA were subjected to Kurtz second harmonic generation (SHG) test using the $\mathrm{Nd}$ :YAG Q-switched laser beam for the nonlinear optical (NLO) property (Kurtz and Perry 1968). The sample of same size was illuminated using Qswitched, mode locked Nd: YAG laser with input pulse of $6.2 \mathrm{~mJ}$. The second harmonic signal of $820 \mathrm{mV}$, 
Table 2. Summarized TGA and DTA results of LAA.

\begin{tabular}{lcccc}
\hline Stage & $\begin{array}{c}\text { Decomposition } \\
\text { temperature range }\left({ }^{\circ} \mathrm{C}\right)\end{array}$ & $\begin{array}{c}\text { Decomposition } \\
\text { steps }\end{array}$ & $\begin{array}{c}\text { Weight loss } \\
\text { observed (\%) }\end{array}$ & Calculated \\
\hline 1 & $200-350$ & $\mathrm{C}_{6} \mathrm{H}_{14} \mathrm{~N}_{4} \mathrm{O}_{2} \mathrm{C}_{2} \mathrm{H}_{4} \mathrm{O}_{2}$ & $58 \cdot 85$ & $56 \cdot 35$ \\
2 & $350-510$ & $\mathrm{C}_{2} \mathrm{H}_{10} \mathrm{~N}_{2} \mathrm{C}_{2} \mathrm{H}_{4}$ & $17 \cdot 16$ & $14 \cdot 51$ \\
3 & $510-680$ & $\begin{array}{c}\downarrow \\
\mathrm{C}_{2} \mathrm{H}_{4} \mathrm{C}_{2} \mathrm{H}_{4}\end{array}$ & $24 \cdot 93$ & $23 \cdot 05$ \\
\hline
\end{tabular}
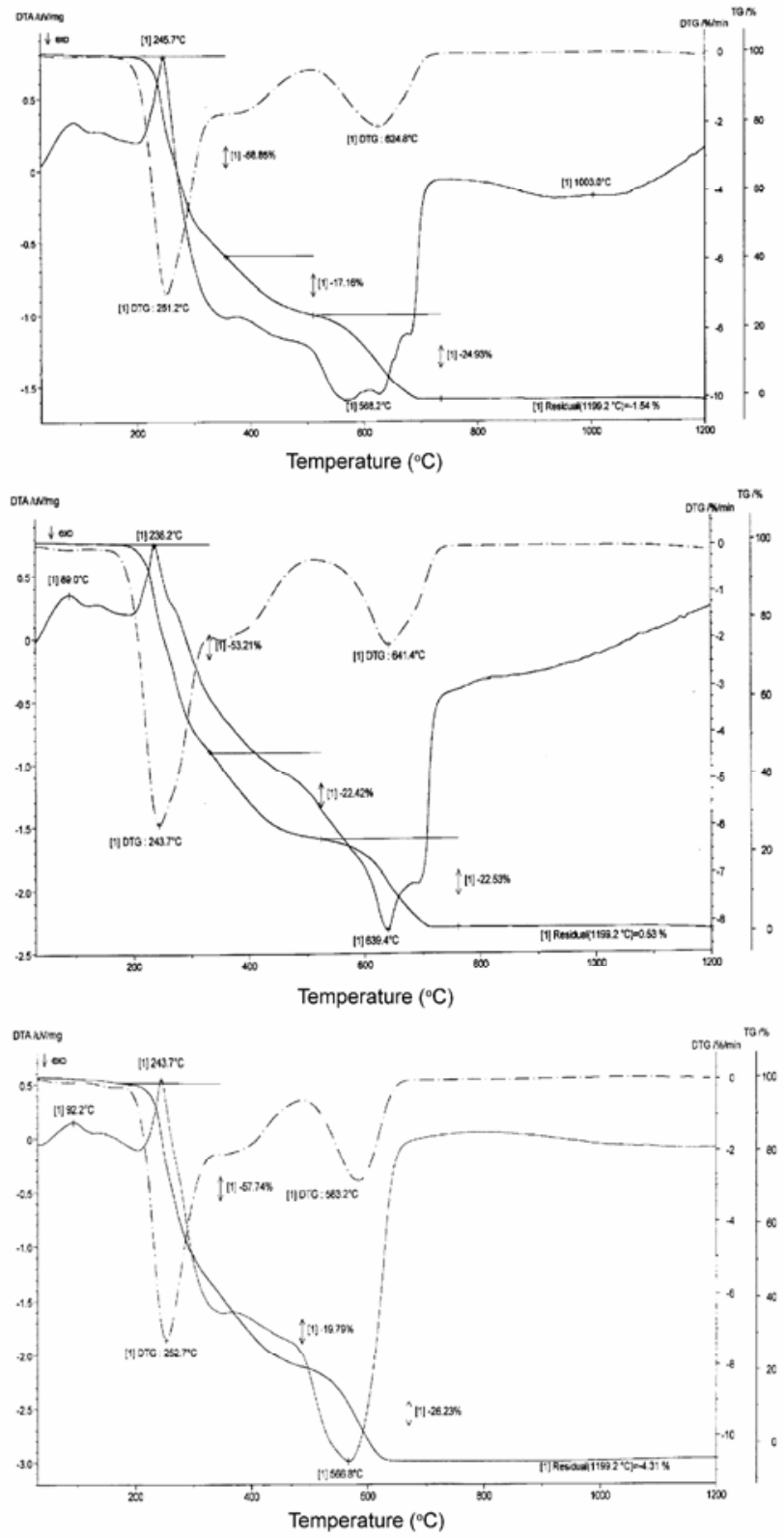

Figure 5. TGA, DTA and DTG curves of pure, $\mathrm{Cu}^{2+}$ and $\mathrm{Mg}^{2+}$ doped LAA single crystals.

$885 \mathrm{mV}$ and $920 \mathrm{mV}$, respectively were obtained for pure, $\mathrm{Cu}^{2+}$ and $\mathrm{Mg}^{2+}$ doped LAA with reference to KDP $(275 \mathrm{mV})$. Thus, the SHG efficiency of pure, $\mathrm{Cu}^{2+}$ and
$\mathrm{Mg}^{2+}$ doped crystals is nearly 3, 3.2 and 3.35 times greater than KDP. It is seen that the $\mathrm{Cu}^{2+}$ and $\mathrm{Mg}^{2+}$ metal dopants have increased the efficiency of pure LAA.

\subsection{Thermal studies}

The thermogravimetric analyses of pure and doped LAA crystals were carried out between 23 and $1200^{\circ} \mathrm{C}$ using STA 409C instrument, in the nitrogen atmosphere at a heating rate of $10 \mathrm{~K} / \mathrm{min}$. Figure 5 shows the resulting TGA and DTG traces of the pure and doped crystals. The sharp weight loss of the material starts around $200^{\circ} \mathrm{C}$. The crystal is completely free of any water of crystallization or any physically adsorbed water on the surface. The absence of significant band in the region $3500-3400 \mathrm{~cm}^{-1}$ confirms the absence of water molecule (Kanagadurai et al 2006). The DTA trace of LAA shows that, there is a sharp endotherm matching with the decomposition of LAA. Heating the material above $200^{\circ} \mathrm{C}$ results in the formation of volatile substances, probably carbon dioxide and ammonia. The $\mathrm{Cu}^{2+}$ doped LAA crystals show same features as that of pure LAA, but there is a distinct shift in the decomposition temperatures. As a result of $\mathrm{Cu}^{2+}$ doping, the peak maximum in DTG corresponding to first stage of decomposition is shifted to lower value $\left(7^{\circ} \mathrm{C}\right)$. The $\mathrm{Mg}^{2+}$ doped LAA crystals show similar features as that of pure LAA, but with a shift in the peak maximum of the first stage of decomposition. Summarized TGA and DTA results are shown in table 2.

\section{Conclusions}

Good quality single crystals of pure, $\mathrm{Cu}^{2+}$ and $\mathrm{Mg}^{2+}$ doped L-arginine acetate (LAA) were grown successfully by slow evaporation technique. X-ray diffraction studies were carried out, and the lattice parameters calculated. Atomic absorption studies of the doped crystals show that the amount of dopant incorporated into the doped crystal is less than the concentration of the dopant in the corresponding solution. The pure and doped LAA crystals are transparent in the entire visible region, and have minimum absorption between 240 and $1380 \mathrm{~nm}$. The TGA and DTG studies show that the metal dopants have not altered the thermal stability of the molecules. NLO stu- 
dies proved that the $\mathrm{Cu}^{2+}$ and $\mathrm{Mg}^{2+}$ metals have increased the efficiency of pure LAA. The presence of dopants has improved the nonlinear optical (NLO) properties of the grown crystals and these crystals can be promising materials for nonlinear device fabrication.

\section{Acknowledgement}

The authors acknowledge the University Grants Commission (UGC), India for funding this research project (F. No. 33-11/2007 (SR)).

\section{References}

Boyd R W 1992 Nonlinear optics (San Diego: Academic Press)
Chemla D S and Zyss J (eds) Nonlinear optical properties of organic molecules and crystals (New York: Academic Press) Vols 1 and 2

Haja Hameed A S, Ravi G, Hossain Md M and Ramasamy P 1999 J. Cryst. Growth 204333

Kanagadurai R, Sankar R, Sivanesan G, Srinivasan S and Jayavel R 2006 Cryst. Res. Technol. 41853

Kurtz S K and Perry T T 1968 J. Appl. Phys. 393798

Monaco S B, Davis L E, Velsko S P, Wang F T and Eimerl D 1987 J. Cryst. Growth 85252

Muralidharan R, Mohan Kumar R, Jayavel R and Ramasamy P 2003 J. Cryst. Growth 259321

Pal T, Kar T, Bocelli G and Rigi L 2003 Cryst. Growth Des. 3 13

Saleh B E and Teich MC 1991 Fundamentals of photonics (New York: Wiley)

Xu D, Jiang M and Tan Z 1983 Acta Chimica Sinica 41570 